\title{
Determination of the coefficient of rolling friction of irregularly shaped maize particles by using discrete element method
}

\author{
Linrong Shi, Wuyun Zhao*, Bugong Sun, Wei Sun \\ (School of Mechanical and Electrical Engineering, Gansu Agricultural University, Lanzhou 730070, China)
}

\begin{abstract}
The coefficient of rolling friction is a foundation parameter for conducting particles simulation, however, which of irregularly shaped maize seeds is difficult to measure. Furthermore, the coefficient of rolling friction between the simulation particles and the actual seeds is inconsistent due to the shaped difference of model and different position of gravity center. This paper use two methods to determinate the coefficient of rolling friction based on discrete element method (DEM) and physical experiments. Three types of maize models from five different shaped maize samples (including horse-tooth shape, spherical cone shape, spherical shape, oblate shape, irregular shape) were developed with the help of slice modeling and 3D modeling technology. Aluminum cylinder container is used to arrange the simulation experiments of angle of repose with taking the coefficient of rolling friction as independent variables and the simulation angle of repose as target values. After predicting detailed the coefficient of rolling friction (including horse-tooth shape, spherical cone shape, spherical shape, between horse-tooth shape and spherical cone shape, between horse-tooth shape and spherical shape, between spherical shape and spherical cone shape maize models), and forecasting a unified the coefficient of rolling friction among horse-tooth shape, spherical cone shape and spherical shape maize models, two types of materials (aluminum cylinder container and organic glass container) were used to validate the difference the angle of repose between the simulation maize models and actual maize seeds. Results show the relative error of the angle of repose between the maize models controlled by the coefficient of rolling friction through the detailed method and the actual maize seeds is $0.22 \%, 0.33 \%$ in aluminum cylinder, organic glass container, respectively. The relative error of the angle of repose between the simulation maize models controlled by the coefficient of rolling friction through the united method and actual maize seeds is $2.47 \%, 2.97 \%$ in aluminum cylinder, organic glass container, respectively. Although the difference of the angle of repose between two method is smaller, the detailed method is better. Moreover, From the accumulation process of the angle of repose we found that the difference on the contacts number between maize models and bottom plate, the change curve of the rotational kinetic energy, the potential energy of maize models controlled by the coefficient of rolling friction through the detailed and the united method are evidently. We can choose a better method to predict the coefficient of rolling friction of maize seeds according to the application situation and investigation objective of irregular maize seeds. The results can provide a theoretical basis for designing and optimizing the structure of the seed-metering machine with DEM.
\end{abstract}

Keywords: coefficient of rolling friction, maize, irregularly shaped model, angle of repose, discrete element method DOI: $10.25165 /$ j.ijabe.20201302.4688

Citation: Shi L R, Zhao W Y, Sun B G, Sun W. Determination of the coefficient of rolling friction of irregularly shaped maize particles by using discrete element method. Int J Agric \& Biol Eng, 2020; 13(2): 15-25.

\section{Introduction}

Discrete element method (DEM) is used to study the law of seeds movement in measurements and provide a theoretical basis for optimizing the structure of measurements, which has been a new trend in recent years ${ }^{[1,2]}$. The reliability of simulation model parameters is crucial to simulation results. Before studying particles flow with DEM, simulation parameters be needed to determinate firstly, which are divided into two categories, namely,

Received date: 2018-10-05 Accepted date: 2020-01-08

Biographies: Linrong Shi, $\mathrm{PhD}$ candidate, Experimentalist, research interests: key technologies and engineering of precision seeding in Northwest Dry Region, Email: shilr@gsau.edu.cn; Bugong Sun, PhD, Professor, research interests: agricultural engineering technology and engineering in Northwest Dry Area, Email: sunbg@gsau.edu.cn; Wei Sun, PhD, Professor, research interests: agricultural engineering technology and engineering in Northwest Dry Area, Email: Sunw@gsau.edu.cn.

*Corresponding author: Wuyun Zhao, PhD, Professor, research interests: farm machine and mechanical reliability. School of mechanical and electrical engineering, Gansu Agricultural University, Lanzhou 730070, China. Tel: +86-451-7632472, Email: zhaowy@gsau.edu.cn. material property parameters and interaction parameters. The material property parameters include shape, size distribution, density, Poisson's ratio and shear modulus. Shape of seeds plays an important role in the behavior of granular materials and is every bit as important as the mechanics of contact ${ }^{[3]}$. The influence of particle shape and inter-particle friction on mechanical response of a granular assembly in a uniaxial compression was determined in laboratory experiment and in DEM simulations ${ }^{[4]}$. It is essential to build a more precise particle model of maize seed assemblies ${ }^{[5]}$. Particles with a higher aspect ratio decrease the bulk density but maintain nearly the same bulk stiffness ${ }^{[6]}$. Particle shape that is closer to the actual shape of particles showed that the increase of flow resistance and the formation of pile-ups ${ }^{[7]}$. A linear relationship is found between the simulation accuracy and the difference between the angularity factor of the approximated shape and the real shape of the particle ${ }^{[8]}$. The interaction parameters consist of the restitution coefficient, the coefficient of static friction and rolling friction coefficient. The research works previously undertaken by other authors have shown that the coefficient of rolling friction can reduce the velocity of particles during the discharge of a flat bottom $\operatorname{bin}^{[9]}$, affect the accumulation 
characteristics of particles ${ }^{[10]}$ or influence the residence time and energy collision between particles ${ }^{[11]}$. The coefficient of static friction has a significant effect on the velocity distribution, porosity distribution, collision frequency, collision energy and power draw in a IsaMill ${ }^{[12]}$. The inter-particle friction reduced the particle re-arrangement in the initial stage but had no significant effect on the deformation stage ${ }^{[13]}$. More accurate input parameters in a simulation yield more accurate calculation results. A simple assumption may decrease the accuracy and credibility of the study results. Thus, a comprehensive value of the rolling friction of a particle group with a broad size distribution and different shapes should be outlined properly. The linear equations of the coefficient of rolling friction and the angle of repose were established $^{[14]}$. The coefficient of rolling friction between maize seeds based on the theory of energy conservation was calculated ${ }^{[15]}$. The simulation and the actual experiment to calibrate the two key parameters of maize seed were combined to determinate the coefficient of static and rolling friction of maize seeds ${ }^{[16]}$.

This paper proposes one method to obtain the coefficient of rolling friction, which is a detailed prediction method. Based on physical and simulation experiments on accumulation of maize seeds, the difference of angle of repose conducted by the coefficient of rolling friction will be compared based on discrete element method (EDEM2018, DEM-Solution, Edinburgh, United Kingdom). Meanwhile, the effect of the coefficient of rolling friction on the maize model's accumulation process will be analyzed in detail.

\section{Particle-contact model}

Maize seed (Longdan No.5) was selected in this research. The water content of this variety as measured by the drying method (drying oven, DHG-9013A, Shanghai Yiheng Instruments Ltd., China) was $13.2 \%$ Inter-particle adhesion can be ignored because of its low water content. Therefore, the contact model of the Hertz-Mindlin (no slip) with relative velocity dependent rolling friction in the EDEM software was selected to simulate the accumulation process of maize seeds.

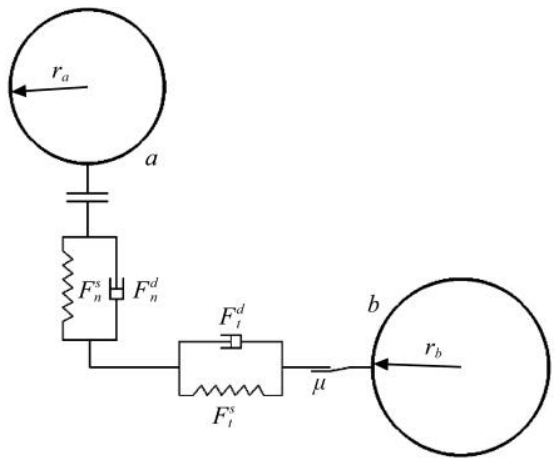

Figure 1 Particle-contact model

The normal and the tangential contact and damping forces are defined as follows:

$$
\begin{aligned}
& F_{n}=F_{n}^{s}+F_{n}^{d} \\
& F_{t}=F_{t}^{s}+F_{t}^{d}
\end{aligned}
$$

In addition, the contact models used ensure that the magnitude of the total contact force in the tangential direction does not exceed the maximum force caused by friction as stated by Coulomb's law of friction:

$$
F_{t}=\left\{\begin{array}{l}
F_{t} \text { if } F_{t}<\mu \cdot F_{n} \\
\mu \cdot F_{n}^{s} \text { if } F_{t} \geq \mu \cdot F_{n}
\end{array}\right.
$$

where, $\mu$ is the friction coefficient.

After calculating the forces $F_{n}$ and $F_{t}$, the gravitational force is added to these two forces to find the resultant force. The resultant force $\left(F_{\text {res }}\right)$ is calculated (vector sum) as:

$$
F_{\text {res }}=F_{n}+F_{t}+{ }_{m g}
$$

where, $m$ and $g$ are the mass of the particle and the gravitational acceleration, respectively, As the tangential component of the contact force causes a moment effect $(M)$, the magnitude of this moment effect is calculated as the product of the tangential force and the perpendicular distance of the contact point from the centre of mass $\left(r_{\text {con }}\right)^{[17]}$. Hence, the moment effect is calculated as:

$$
\begin{aligned}
& M=r_{\text {con }} \cdot F_{t} \\
& \frac{1}{r_{e q}}=\frac{1}{r_{a}}+\frac{1}{r_{b}}
\end{aligned}
$$

where, $r$, are the radius for the individual particles $a$ and $b$, respectively.

In a granular system, the rolling resistance dissipates energy during relative rotation, and provides "packing support" that gives the stability of the granular system. So, an additional moment is also applied to the contacting surfaces as,

$$
M_{r}=-\mu_{r} \cdot F_{n}^{s} \cdot r_{c o n} \cdot \lambda_{\dot{\theta}}
$$

where, $M_{r}$ is the moment due to rolling friction; $\mu_{r}$ si the coefficient of rolling friction, and $\lambda_{\dot{\theta}}$ is the unit vector of angular velocity

$(\dot{\theta})$ at the contact point. The resultant moment $\left(M_{r e s}\right)$ is calculated (vector sum) as:

$$
M_{\text {res }}=M+M_{r}
$$

In order to update the new position of the particle, the acceleration of the particle is calculated by using Newton's second law of motion. The translational and the rotational accelerations of the particle are found as:

$$
\begin{gathered}
\ddot{U}=\frac{F_{r e s}}{m} \\
\ddot{\theta}=\frac{M_{r e s}}{I}
\end{gathered}
$$

where, $\ddot{U}, \ddot{\theta}, m$, and $I$ are the translational acceleration, the rotational acceleration, the mass of the particle, and the moment of inertia of the particle, respectively. After calculating the velocity, the new positioning of the particle is computed by integrating the velocity over the time interval.

In the HMCM normal and tangential contact and damping forces between two particles are defined as:

$$
F_{n}^{s}=-K_{n} \cdot U_{a b n}^{3 / 2}
$$

where, $U_{a b n}$ is the normal component of the relative displacement and $K_{\mathrm{n}}$ is the normal stiffness which is defined as,

$$
\begin{gathered}
K_{n}=2 \cdot E_{e q} \cdot \sqrt{r_{e q} \cdot U_{a b n}} \\
\frac{1}{E_{e q}}=\frac{\left(1-v_{a}^{2}\right)}{E_{a}}+\frac{\left(1-v_{b}^{2}\right)}{E_{b}}
\end{gathered}
$$

where, E, v, are Young's modulus, Poisson's ratio for the individual particles $a$ and $b$, respectively.

The tangential contact force was defined as per Mindlin as:

$$
F_{t}^{s}=-K_{t} \cdot U_{a b t}
$$

where, $K_{t}$ is the tangential stiffness as defined by Mindlin as:

$$
\begin{gathered}
K_{t}=8 \cdot G_{e q} \cdot \sqrt{r_{e q} U_{a b n}} \\
\frac{1}{G_{e q}}=\frac{2-v_{a}}{G_{a}}+\frac{2-v_{b}}{G_{b}}
\end{gathered}
$$

where, $G$ is shear modulus for the individual particles $a$ and $b$, 
respectively.

The normal and tangential damping forces were determined as:

$$
\begin{gathered}
F_{n}^{d}=-2 \cdot \sqrt{\frac{5}{6}} \cdot \psi \cdot \sqrt{K_{n} \cdot m_{e q}} \cdot \dot{U}_{a b n} \\
F_{t}^{d}=-2 \cdot \sqrt{\frac{5}{6}} \cdot \psi \cdot \sqrt{K_{t} \cdot m_{e q}} \cdot \dot{U}_{a b t} \\
\frac{1}{m_{e q}}=\frac{1}{m_{a}}+\frac{1}{m_{b}}
\end{gathered}
$$

where, $e$ is the coefficient of restitution of the particles; $m$ is the mass for the individual particles $a$ and $b$, respectively.

\section{Materials and parameters}

Based on Hertz-Mindlin contact model, simulation parameters of maize models can be divided into two categories, namely, material property parameters and interaction parameters. The material property parameters include shape, size distribution, density, Poisson's ratio, and shear modulus. The interaction parameters consist of the restitution coefficient, the coefficient of static friction and rolling friction coefficient

\subsection{Maize shape and the percentage of each shape}

The shape of maize seed (Longdan No.5, China) of the same variety varies from each other. To ensure the consistency of experimental and simulation results, characteristics of maize seeds was classified. 1000 maize seeds were selected randomly to classify as horse tooth shape, spherical cone shape, spherical shape, oblate shape and irregular shape (Figure 2) and determine the quantity ratio (Figure 3). The front and back outlines of a horse-tooth are trapezoids, and its width is much larger than its thickness. The top of a spherical-cone is like to the horse-tooth shape, and its bottom can be approximated by a semi-sphere. The width of a spherical cone differs a little from its thickness. The spherical can be approximated by a sphere, its surface is rather rounded. The prism has a slender figure, and there are three obvious edges on it. The other shapes of maize seeds are defined as irregular shapes.

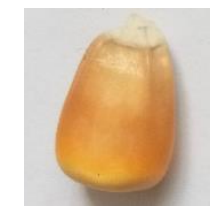

a. Horse tooth shape

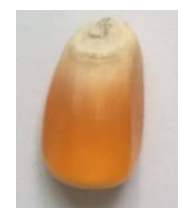

b. Spherical cone shape

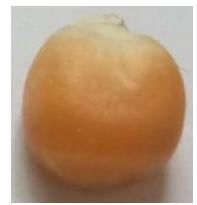

c. Spherical shape

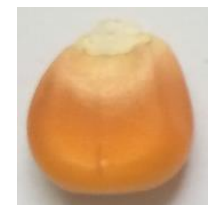

d. Oblate

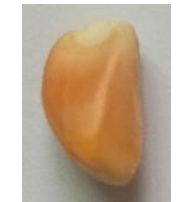

e. Irregular-shape
Figure 2 Geometrical shape classification of maize seeds Longdan No.5

A total of 1000 maize seeds are randomly selected from the same variety and classified according to the abovementioned shape features. The results showed that the percentages of horse-tooth shape, spherical cone shape, spherical shape, ablate shape, irregular shape are $39.7 \%, 42.7 \%, 8.7 \%, 6.0 \%$ and $2.9 \%$, respectively. The sum of the horse-tooth shape, spherical cone shape, spherical shape maize seeds account for almost $91.1 \%$ of the total. Therefore, to simplify the modelling of maize seed, horse-tooth shape, spherical cone shape, and spherical shape maize seeds are selected to model.

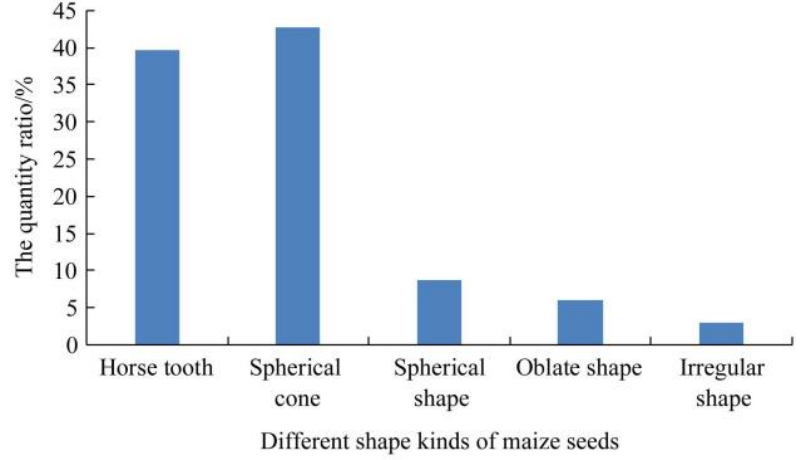

Figure 3 Percentage of each shape of maize seeds for Longdan No.5

\subsection{Size distribution}

To easily estimate the volume distribution of maize seeds, the characteristic sizes of horse-tooth shape are defined as the upper base $\left(W_{1}\right)$, lower base $\left(W_{2}\right)$, height $\left(W_{2}\right)$, thickness $(T)$, as shown in Figure $4 \mathrm{a}$. For spherical cone shape maize size, the characteristic sizes are defined as the upper diameter $\left(D_{1}\right)$, lower diameter $\left(D_{2}\right)$, height $(H)$, as shown in Figure $4 \mathrm{~b}$. The geometrical shape of spherical shape maize seeds is the diameter $(D)$, as shown in Figure $4 \mathrm{c}$. The characteristic sizes of these three varieties are measured by a digital caliper with an accuracy of $0.01 \mathrm{~mm}$. The volume of three shaped maize seeds are estimated by Equations (16)-(18).

$$
\begin{gathered}
V_{1}=\frac{T}{2}(H-T)\left(W_{1}+W_{2}\right)+\frac{\pi}{8} T^{2}\left(W_{1}+W_{2}-2 T\right)+\frac{\pi}{12} T^{2} \\
V_{2}=\frac{2 \pi}{3}\left(\left(\frac{D_{1}}{2}\right)^{3}+\left(\frac{D_{2}}{2}\right)^{3}\right)+ \\
\frac{\pi}{3}\left(H-\frac{D_{1}}{2}-\frac{D_{2}}{2}\right)\left(\left(\frac{D_{1}}{2}\right)^{2}+\left(\frac{D_{2}}{2}\right)^{2}+\frac{D_{1} D_{2}}{4}\right) \\
V_{2}=\frac{\pi D^{3}}{6}
\end{gathered}
$$

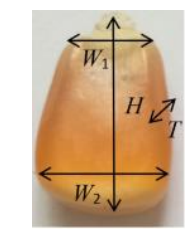

a. Horse tooth shape

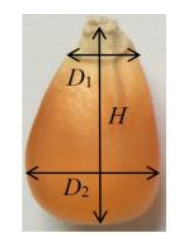

b. Spherical cone shape

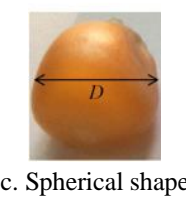

c. Spherical shape
Figure 4 Characteristic sizes of maize seeds

The volume distributions of the maize seeds are shown in Figure 5. It can be found that the all volume distribution of three shape types of maize seeds roughly obey a normal distribution. For horse tooth shape maize seed, the average volume $V_{1}$ is $311.11 \mathrm{~mm}^{3}$, this is $H$ is $12.56 \mathrm{~mm}$, and $W_{1}$ is $6.02 \mathrm{~mm}$, and $W_{2}$ is $8.44 \mathrm{~mm}$, and $T$ is $4.51 \mathrm{~mm}$, and standard deviation is $0.11 V_{1}$. For spherical cone shape maize seed, the average volume $V_{2}$ is $269.75 \mathrm{~mm}^{3}$, this is $D_{1}=5.22 \mathrm{~mm}$, and $D_{2}=6.98 \mathrm{~mm}$, and $L=$ $10.96 \mathrm{~mm}$, and standard deviation is $0.15 V_{2}$. For spherical shape maize seed, the average volume $V_{3}$ is $181.37 \mathrm{~mm}^{3}$, this is $D=$ $7.02 \mathrm{~mm}$, and standard deviation is $0.19 V_{3}$.

\subsection{Maize seeds model}

The modelling process for a single maize models is followed: the maize seeds that the primary size (horse tooth shape, spherical cone shape, and spherical shape) are closer to its mean value are selected from 200 seeds, respectively. 3D model template of maize seeds were modeled with using technology of slicing modeling ${ }^{[23]}$, operation process of which: maize seeds that are close to the average value are selected for maize slicing, and the camera 
is used to image slice acquisition, and the contour of maize slices is traced with 2004 CAD software, and the above operations are repeated, and the contour of all maize slices is imported into the 3D modeling software to establish the corn model. and those DEM models is built using the multi-spheres method with 11 sub-spheres, 3 sub-spheres and one sphere for the horse tooth shape, spherical cone shape and spherical shape maize seeds, as shown in Figure $6^{[24,25]}$. The maize models assembly are generated according to abovementioned the volume distribution. 845 maize models are selected on the proportion of 13:14:3 as horse tooth shape, spherical cone shape, spherical shape maize seeds.
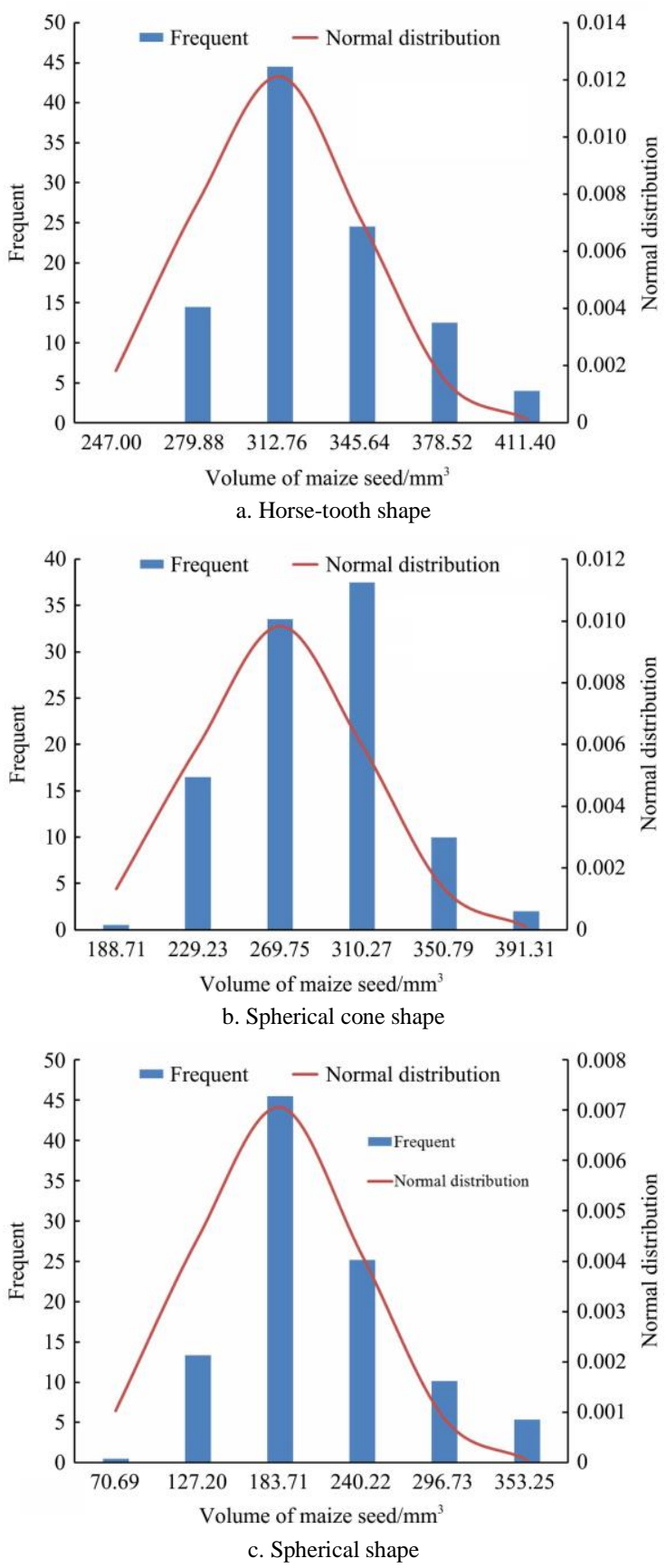

Figure 5 Volume distribution of maize seeds

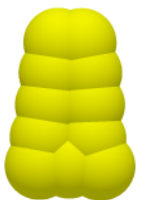

a. Horse-tooth shape b. Spherical cone shape

\subsection{Material properties}

With reference to ASAE Standards ${ }^{[18]}$ and literature ${ }^{[19]}$, Poisson's ratio of maize seeds is 0.4 , and its Shear Modulus is $1.37 \times 10^{8} \mathrm{~Pa}$. The density of maize seeds was calculated on the mass and the volume measured through the drainage method which is the volume of water discharged from maize seeds after they are placed in test tubes filled fully with water, and the maize density is $1180 \mathrm{~kg} / \mathrm{m}^{3}$. The interaction parameters consist of the restitution coefficient, the coefficient of static friction and the coefficient of rolling friction ${ }^{[20]}$. The coefficient of static friction and the restitution coefficient have critical influence on the particle-discharge behavior ${ }^{[21]}$. The coefficient of restitution between maize seeds is one of the key properties of maize seeds required in numerical simulation, which is $0.37^{[22]}$. The coefficient of static friction between maize seeds is $0.2^{[23]}$. The coefficient of rolling friction will occur when two bodies roll relatively. The coefficient of rolling friction of particles is the basis for design and improvement of particles-processing interaction machines ${ }^{[14]}$. In particular, the particles of irregular shape and its contact area between simulation maize model and actual maize seeds are different. Therefore, the coefficients of rolling friction are different from the actual that and are needed to calibrate before the simulation analysis of maize seeds. Other property parameters and interaction parameters are listed in Table 1.

Table 1 Other physical parameters used in the DEM simulation $^{[26]}$

\begin{tabular}{clc}
\hline Simulation condition & \multicolumn{1}{c}{ Parameters } & Value \\
\hline \multirow{2}{*}{ Aluminum cylinder } & Poisson ratio & 0.34 \\
& Shear modulus/Pa & $2.5 \times 10^{10}$ \\
& density $/ \mathrm{kg} \cdot \mathrm{m}^{-3}$ & 2700 \\
& Poisson ratio & 0.35 \\
Organic glass & Shear modulus/Pa & $1.3 \times 10^{9}$ \\
& density $/ \mathrm{kg} \cdot \mathrm{m}^{-3}$ & 1200 \\
& Coefficient of restitution & 0.729 \\
Maize seeds and aluminum & Coefficient of static friction & 0.342 \\
& Coefficient of dynamic friction & 0.052 \\
& Coefficient of restitution & 0.621 \\
Maize seeds and organic glass & Coefficient of static friction & 0.459 \\
& Coefficient of dynamic friction & 0.093 \\
\hline
\end{tabular}

\section{Repose accumulation}

To make simulation result close to reality, two types of container are used to form the angle of repose of maize seeds, including the organic glass container (length is $100 \mathrm{~mm}$, width is $60 \mathrm{~mm}$, height is $110 \mathrm{~mm}$ ) and the aluminum cylinder (inner diameter is $54 \mathrm{~mm}$, height is $300 \mathrm{~mm}$ ), as shown in Figure 7. The varieties of maize seeds are Longdan No.5. The maize seeds angle of repose under organic glass are measured as follow: the baffle is pulled upwards at a uniform speed of $20 \mathrm{~mm} / \mathrm{s}$ driven by Electric Push-pull Rod (YS, DC: 12V). When the flow of the maize seeds is stable, the angle between the maize population slope and the horizontal plane is the angle of repose. Maize angle of repose under aluminum cylinder are measured as follow: the cylinder bottom is fitted with the table, and the cylinder is pulled upwards at a uniform speed of $20 \mathrm{~mm} / \mathrm{s}$ driven by Electric Push-pull Rod (YS, DC: $12 \mathrm{~V}$ ). While the population is stable, the angle between the population slope and the horizontal plane is the angle of repose. Because of the conical accumulation of

Figure 6 Discrete element models of maize seeds 
maize seeds population under the condition of aluminum cylinder, images of angle of repose were collected from $x$ and $y$ directions, respectively, as shown in Figure 7c.

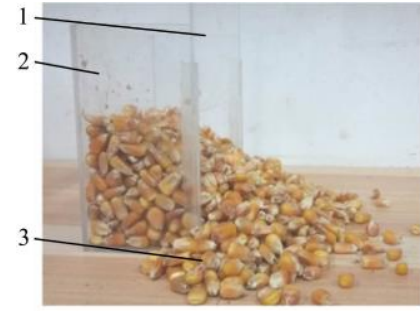

1. Baffle 2. Case 3. Maize seeds a. Organic glass container

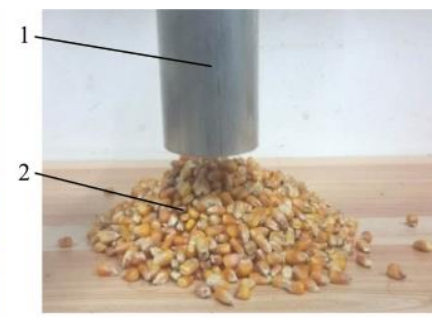

$\begin{array}{ll}\text { 1. Aluminum cylinder } \quad \text { 2. Maize seeds } & \end{array}$ b. Aluminum cylinder

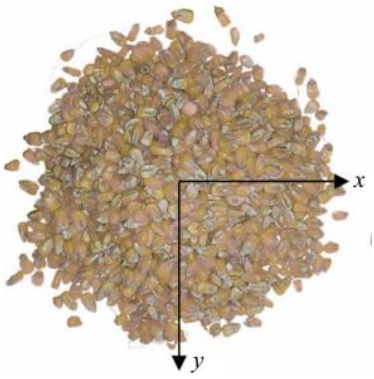

c. Direction of angle of repose

Figure 7 Experimental angle of repose of maize seeds
845 horse-tooth shape (or spherical cone shape, or spherical shape) maize seeds were used to form the angle of repose. To obtain the stability value of angle of repose of maize seeds, the angles of repose were measured under aluminum cylinder and 6 times in each type, as shown in Table 2. The average angle of repose of horse tooth shape, spherical cone shape, spherical shape maize seeds under aluminum cylinder is $19.61^{\circ}, 18.80^{\circ}, 16.82^{\circ}$, respectively.

Table 2 Angles of repose tested in the laboratory

\begin{tabular}{cccccccccc}
\hline Material & \multicolumn{4}{c}{ Angle of repose/( $\left(^{\circ}\right)$} & & $\begin{array}{c}\text { Average } \\
\text { value/ }\left(^{\circ}\right)\end{array}$ & $\begin{array}{c}\text { STDEV } \\
/\left(^{\circ}\right)\end{array}$ \\
\hline $\begin{array}{c}\text { Horse tooth } \\
\text { shape }\end{array}$ & 19.67 & 20.79 & 18.88 & 19.27 & 19.51 & 19.52 & 19.61 & 0.64 \\
$\begin{array}{c}\text { Spherical } \\
\text { cone shape } \\
\begin{array}{c}\text { Spherical } \\
\text { shape }\end{array}\end{array}$ & 18.24 & 18.93 & 18.85 & 18.61 & 19.68 & 18.48 & 18.80 & 0.50 \\
\hline
\end{tabular}

4.1 Detailed prediction of coefficient of rolling friction of maize models

4.1.1 The individual coefficient of rolling friction of horse tooth shape, spherical cone shape and spherical shape maize models

Relationship between the coefficient of rolling friction and the angle of repose of three shape types of maize seeds as shown in Figure 8.
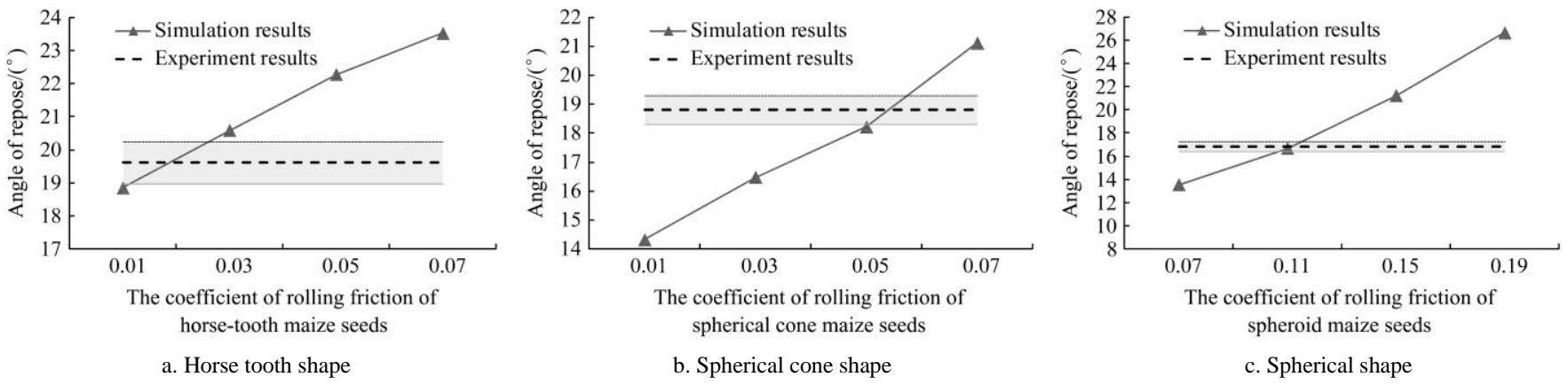

Figure 8 Relationship between the coefficient of rolling friction and the angle of repose of three shape types of maize seeds

In the simulation experiments, the simulation angle of repose of horse tooth shape, spherical cone shape maize models were obtained by changing the coefficient of rolling friction, which is $0.01,0.03,0.05$ and 0.07 , respectively. The predictive coefficient of rolling friction of horse tooth shape maize seeds is 0.018 through Equation (19). The predictive coefficient of rolling friction of spherical cone shape maize models is 0.051 from Equation (20). The simulation angle of repose of spherical shape maize seeds was gained by changing the coefficient of rolling friction, which is 0.07 , $0.11,0.15$ and 0.19 , respectively. The predictive coefficient of rolling friction of spherical maize seeds is 0.105 from Equation (21).

$$
\begin{aligned}
& y=78.65 x+18.16 \\
& y=110.58 x+13.11 \\
& y=109.5 x+5.28
\end{aligned}
$$

where, $y$ is the angle of repose of maize seeds, and $x$ is the coefficient of rolling friction.

When the angle of repose of three shape types of maize seed all reached $20^{\circ}$, the predictive coefficient of rolling friction of horse tooth shape, spherical cone shape, spherical shape maize seeds is $0.023,0.062,0.13$, respectively from the Equations (19)-(21). It can be realized that the rolling friction force of spherical shape maize seeds was greater than that of other two non-spherical maize models to approach the same the angle of repose. Meanwhile, it shows that the shape of the maize seed affects the coefficient of rolling friction. Furthermore, it is necessary to determine the coefficient of rolling friction of maize seeds in this paper.

4.1.2 The coefficient of rolling friction of mixed spherical shape and horse tooth shape maize models

The samples of 200 horse tooth shape and 200 spherical shape maize seeds were mixed to form the angle of repose. The actual angle of repose of maize seeds was measured under aluminum cylinder in 5 times, as shown in Table 3 . The average experimental angle of repose in $x, y$ direction under test conditions is $18.28^{\circ}, 17.94^{\circ}$, respectively, and the average angle of repose is $18.11^{\circ}$.

Table 3 Angles of repose of mixed horse tooth shape and spherical shape maize seeds experimented in the laboratory

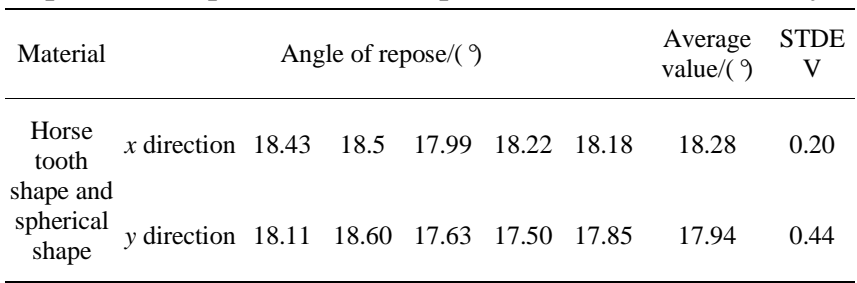

According to above the results, the coefficient of rolling friction between horse tooth shape maize seeds is 0.023 , and that 
between spherical shape maize seeds is 0.13 , the angles of repose of mixed horse tooth shape and spherical shape maize models were obtained by changing the coefficient of rolling friction between horse-tooth shape and spherical shape maize models, which is 0.01 , $0.05,0.1$ and 0.15 , respectively, and angles of repose of mixed spherical shape and horse tooth shape maize models are shown in Table 4. Relationship between the coefficient of rolling friction and the angle of repose of mixed horse tooth shape and spherical shape maize models is shown in Equation (22). As the Equation (22) is unreliable, the predictive coefficient of rolling friction between horse tooth shape and spherical shape maize seeds is 0.05 according to Figure 9.

$$
y=1.8533 x+18.439
$$

Table 4 Simulation angles of repose of mixed spherical shape and horse tooth shape maize models

\begin{tabular}{cccc}
\hline $\begin{array}{c}\text { Coefficient of } \\
\text { rolling friction }\end{array}$ & $\begin{array}{c}\text { Angle of repose in } x \\
\text { direction } /\left(^{\circ}\right)\end{array}$ & $\begin{array}{c}\text { Angle of repose in } y \\
\text { direction } /\left(^{\circ}\right)\end{array}$ & $\begin{array}{c}\text { Average } \\
\left.\text { value/ } /{ }^{\circ}\right)\end{array}$ \\
\hline 0.01 & 18.70 & 18.41 & 18.56 \\
0.05 & 19.11 & 17.69 & 18.40 \\
0.1 & 18.6 & 18.6 & 18.60 \\
0.15 & 17.24 & 19.05 & 18.77 \\
\hline
\end{tabular}

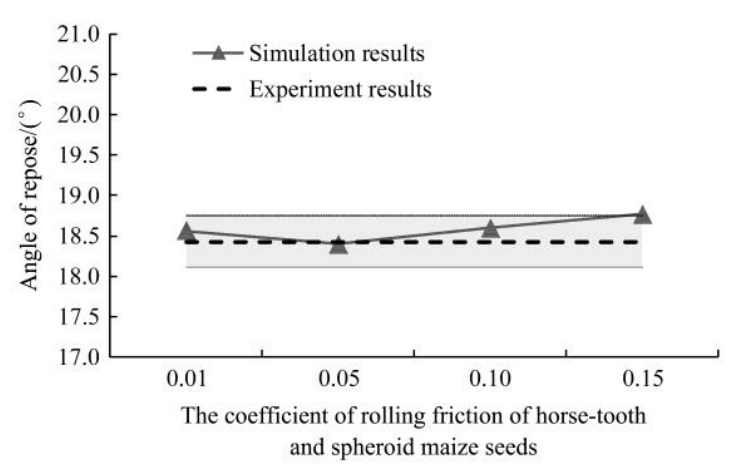

Figure 9 Relationship between the coefficient of rolling friction and the angle of repose of mixed horse tooth shape and spherical shape maize models

4.1.3 The coefficient of rolling friction of mixed spherical cone shape and spherical shape maize seeds

200 spherical cone shape and 200 spherical shape maize seeds were mixed to form the angle of repose. The actual angle of repose of maize seeds were measured under aluminum cylinder in 5 times, as shown in Table 5. The experimental average angle of repose in $x, y$ direction is $19.94^{\circ}, 20.17^{\circ}$, respectively, and the average angle of repose is $20.06^{\circ}$.

Table 5 Angles of repose of mixed spherical cone shape and spherical shape maize seeds experimented in the laboratory

\begin{tabular}{ccccccccc}
\hline Material & & \multicolumn{4}{c}{ Angle of repose $/\left(^{\circ}\right)$} & & $\begin{array}{c}\text { Average } \\
\left.\text { value/( }{ }^{\circ}\right)\end{array}$ & $\begin{array}{c}\text { STDE } \\
\text { V }\end{array}$ \\
\hline $\begin{array}{c}\text { Horse tooth } \\
\text { shape and } \\
\text { spherical } \\
\text { cone shape }\end{array}$ & $y$-direction & 20.6 & 18.71 & 19.51 & 20.00 & 20.87 & 19.94 & 0.87 \\
& & & & & & & & \\
\end{tabular}

According to above the results, the coefficient of rolling friction between horse tooth shape maize seeds is 0.023 , and that between spherical cone shape maize seeds is 0.062 . The simulation angle of repose of mixed spherical cone shape and spherical shape maize seeds was obtained by changing the coefficient of rolling friction between spherical cone shape and spherical shape maize seeds, which is $0.05,0.1,0.15$ and 0.20 , respectively, and angles of repose of mixed spherical cone shape and spherical shape maize models are shown in Table 6. The predictive coefficient of rolling friction of mixed spherical cone shape and spherical shape maize models is 0.17 . As shown in Equation (23). Relationship between the coefficient of rolling friction and the angle of repose of mixed spherical cone shape and spherical shape maize models is shown in Figure 10.

$$
y=36.72 x+14.84
$$

Table 6 Simulation angles of mixed spherical cone shape and spherical shape maize models

\begin{tabular}{cccc}
\hline $\begin{array}{c}\text { Coefficient of } \\
\text { rolling friction }\end{array}$ & $\begin{array}{c}\text { Angle of repose in } x \\
\text { direction } /\left(^{\circ}\right)\end{array}$ & $\begin{array}{c}\text { Angle of repose in } y \\
\text { direction } /\left(^{\circ}\right)\end{array}$ & $\begin{array}{c}\text { Average } \\
\text { value/ } /\left(^{\circ}\right)\end{array}$ \\
\hline 0.05 & 16.03 & 15.54 & 15.79 \\
0.1 & 17.97 & 17.13 & 17.55 \\
0.15 & 19.14 & 18,66 & 18.90 \\
0.20 & 21.23 & 21.69 & 21.46 \\
\hline
\end{tabular}

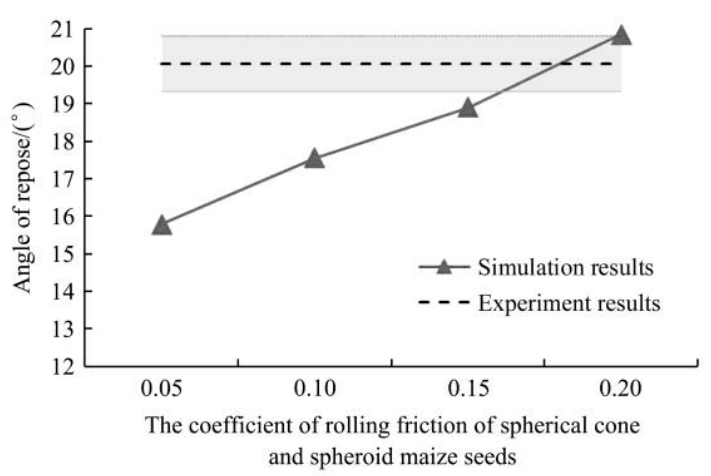

Figure 10 Relationship between the coefficient of rolling friction and the angle of repose of mixed spherical cone shape and spherical shape maize models

4.1.4 Coefficient of rolling friction of mixed horse tooth shape and spherical cone shape maize seeds

200 horse tooth shape and 200 spherical cone shape maize seeds were mixed to form the angle of repose. The actual angle of repose of maize seeds was measured under aluminum cylinder in 5 times, as shown in Table 5. The average experimental angle of repose in $x, y$ direction is $23.55^{\circ}, 23.79^{\circ}$, respectively, and the average angle of repose is $23.67^{\circ}$, as shown in Table 7 .

Table 7 Angles of repose of mixed horse tooth shape and spherical cone shape maize seeds experimented in the laboratory

\begin{tabular}{ccccccccc}
\hline Material & & \multicolumn{4}{c}{ Angle of repose $/\left(^{\circ}\right)$} & & $\begin{array}{c}\text { Average } \\
\text { value/ }\end{array}$ & STDEV \\
\hline $\begin{array}{c}\text { Horse-tooth } \\
\text { and } \\
\text { spherical }\end{array}$ & $x$-direction & 22.88 & 23.88 & 22.42 & 24.48 & 24.10 & 23.55 & 0.87 \\
\hline
\end{tabular}

According to above the results, the coefficient of rolling friction between spherical cone shape maize seeds is 0.062 , and that between spherical shape maize seeds is 0.13 . the simulation angle of repose of mixed horse tooth shape and spherical cone shape maize seeds was obtained by changing the coefficient of rolling friction between horse tooth shape and spherical cone shape maize seeds, which is $0.01,0.05,0.1$ and 0.15 , respectively, and angles of repose of mixed horse tooth shape and spherical cone shape maize models are shown in Table 8 . The predictive coefficient of rolling friction of mixed horse tooth shape and spherical cone shape maize models is 0.068. As shown in Equation (24). Relationship between the coefficient of rolling friction and the angle of repose of mixed horse tooth 
shape and spherical cone shape maize models is shown in Figure 11.

$$
y=5.4086 x+23.301
$$

Table 8 Simulation angles of repose of mixed horse tooth shape and spherical cone shape maize models

\begin{tabular}{cccc}
\hline $\begin{array}{c}\text { The coefficient of } \\
\text { rolling friction }\end{array}$ & $\begin{array}{c}\text { Angle of repose in } x \\
\text { direction } /\left(^{\circ}\right)\end{array}$ & $\begin{array}{c}\text { Angle of repose in } y \\
\text { direction } /\left(^{\circ}\right)\end{array}$ & $\begin{array}{c}\text { Average value } \\
/\left(^{\circ}\right)\end{array}$ \\
\hline 0.01 & 23.47 & 23.14 & 23.31 \\
0.05 & 23.58 & 23.64 & 23.61 \\
0.1 & 23.8 & 23.98 & 23.89 \\
0.15 & 24.1 & 24.03 & 24.07 \\
\hline
\end{tabular}

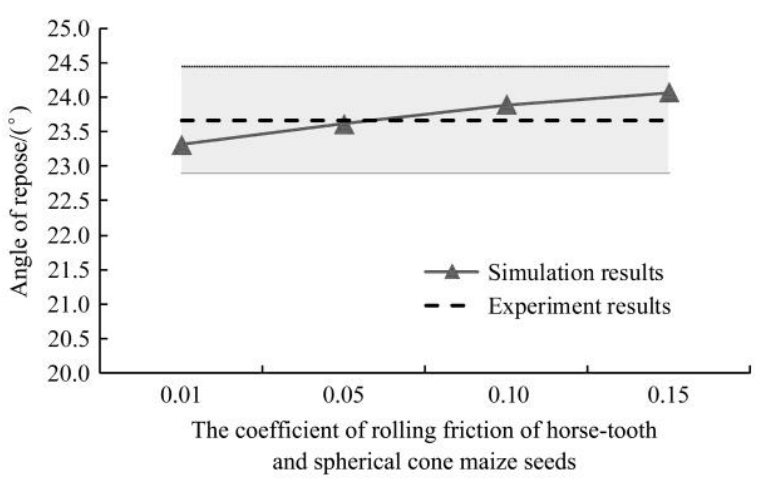

Figure 11 Relationship between the coefficient of rolling friction and the angle of repose of mixed horse-tooth and spherical cone maize models

Comparing the results of Table 2, Table 3, Table 5 and Table 7, we can see that the angle of repose from two shape type mixed maize seeds are greater than that from one type shape of maize seeds. This is because non-spherical maize seeds (horse tooth shape and spherical cone shape) reduces the flow of maize seeds in the accumulation process and increases the angle of repose of maize seeds. Comparing the results of Figure 9 and Figure 10, it seems that the samples containing "horse tooth" particles are quite insensitive to the variation of the rolling coefficient of friction. This is because shape of non-spherical maize seeds limiting the angle of repose in the accumulation process.

4.1.5 Verification of simulation results

To verify the reliability of the coefficient of rolling friction obtained above, a comparative experiment of the repose of angle was carried out under two types of containers (aluminum cylinder and organic glass). 845 maize seeds were produced according to the proportion of 13:14:3 as horse tooth shape, spherical cone shape, spherical shape in simulation. According to above the results, we can know that the coefficient of rolling friction of horse tooth shape, spherical cone shape, spherical shape maize seeds is $0.023,0.062,0.13$, respectively, and the coefficient of rolling friction between horse tooth shape and spherical shape, between spherical cone shape and spherical shape, between horse tooth shape and spherical cone shape maize seeds is $0.05,0.17,0.068$, respectively. The simulation and actual angle of repose under the condition of aluminum cylinder are shown as Figures 12 and 13, respectively. From Figures 12 and 13 the average simulation, actual angle of repose is $27.22^{\circ}, 27.16^{\circ}$, respectively. Comparing the simulation and actual angle of repose of maize seeds, the relative error of which is $0.22 \%$. The simulation and actual range of angle of repose is basically coincident, this is the height of angle of repose is basically $40 \mathrm{~mm}$, and the diameter is basically $170 \mathrm{~mm}$.

The simulation and actual angles of repose of maize seeds under the condition of organic glass container show as Figure 14. From Figure 14 the average simulation, actual angle of repose is $28.84^{\circ}, 28.93^{\circ}$, respectively. Comparing the simulation and actual angle of repose, the relative error of which is $0.31 \%$.

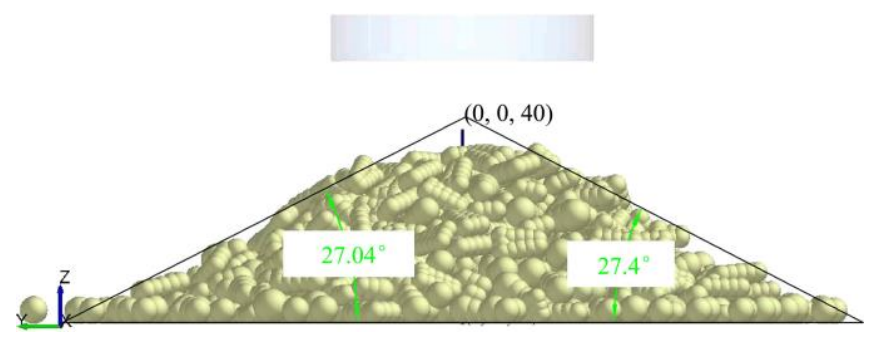

a.

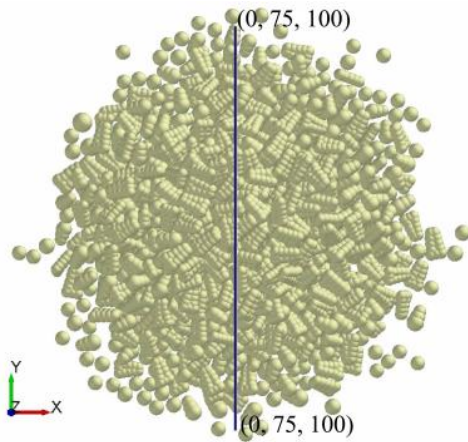

b.

Figure 12 Generation of simulation maize models pile (a) and top view (b) of maize repose under the condition of aluminum cylinder

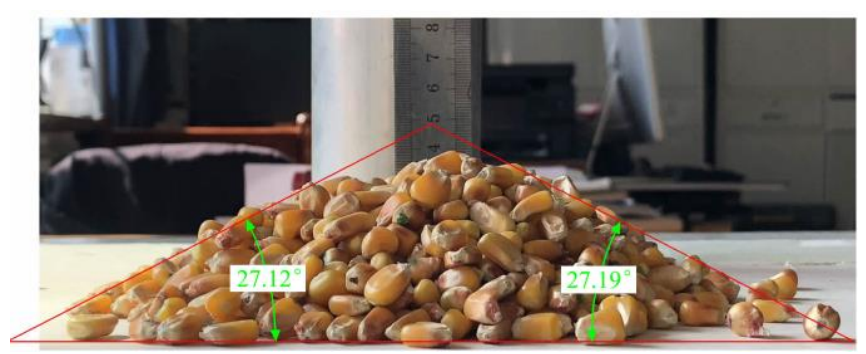

a.

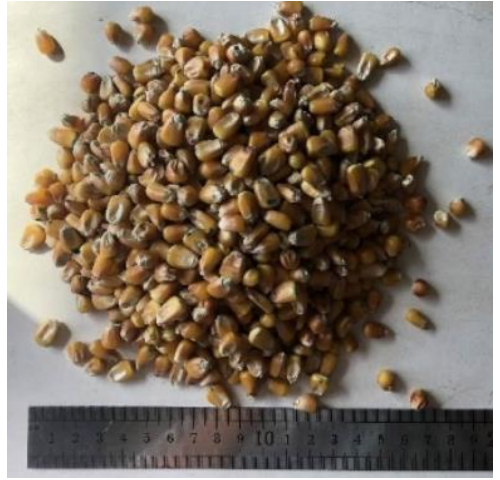

b.

Figure 13 Generation of actual maize models pile (a) and top view (b) of maize repose under the condition of aluminum cylinder 


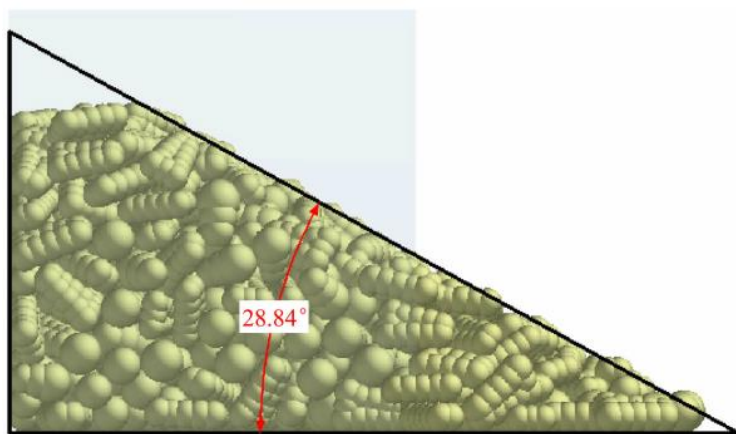

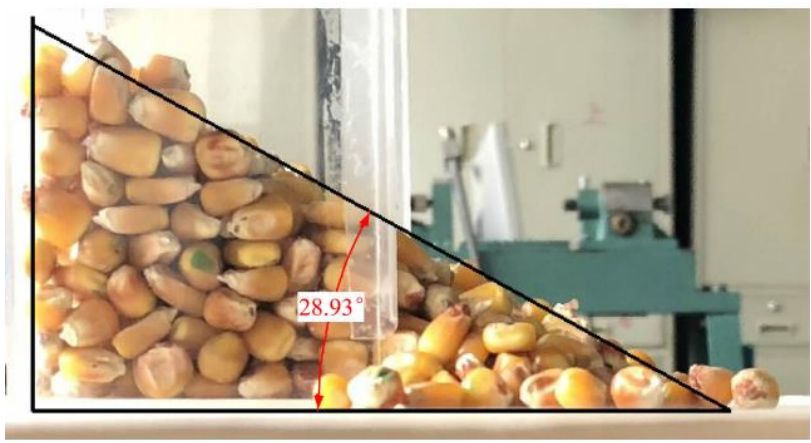

b.

Figure 14 Generation of maize repose under the condition of organic glass container (a) Simulation angle of repose, (b)Actual angle of repose

\subsection{United prediction of coefficient of rolling friction of maize models}

4.2.1 Prediction of the unified coefficient of rolling friction

To compare the reliability of the method to predict the coefficient of rolling friction used in literature paper, and errors of the angle of repose between two different methods were compared under the same condition. 845 maize seeds were produced according to the proportion of $13: 14: 3$ as horse tooth shape, spherical cone shape, spherical shape in simulation. The fixed coefficient of static friction between maize seeds is 0.2 . According to the literature ${ }^{[27]}$, the range of the coefficient of rolling friction between maize seeds are 0.005 to 0.18 . In this paper the coefficient of rolling friction of maize seeds is set to $0.01,0.05$, 0.09 and 0.13 . 4 groups the simulation angle of repose of mixed horse tooth shape, spherical cone shape and spherical shape maize seeds were measured under aluminum cylinder. Arrangement of the coefficient of rolling friction and the simulation angle of repose is shown in Table 9. Relation between the predictive coefficient of rolling friction and angle of repose is shown in Figure 15.

Table 9 Arrangement of the coefficient of rolling friction and the simulation angle of repose

\begin{tabular}{ccc}
\hline Number & $\begin{array}{c}\text { The coefficient of rolling friction } \\
\text { of maize seeds }\end{array}$ & $\begin{array}{c}\text { Angle of repose } \\
/\left(^{\circ}\right)\end{array}$ \\
\hline 1 & 0.01 & 21 \\
2 & 0.05 & 24.31 \\
3 & 0.09 & 27.23 \\
4 & 0.13 & 29.61 \\
\hline
\end{tabular}

Figure 15 shows that the angle of repose tends to increase with an increase in the coefficient of rolling friction. This phenomenon occurs because the increased coefficient of rolling friction results in an increased rolling resistance when the maize particles interact with the contact surface. Maize models cannot scatter easily on the bottom plate.

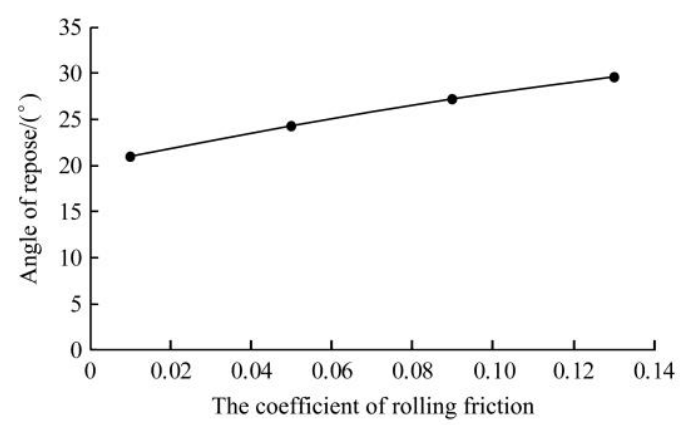

Figure 15 Relation between the predictive coefficient of rolling friction and angle of repose
Fitting is performed on the data points in Figure 15 to determine the relationship between the inter-models coefficient of rolling friction and the angle of repose as shown in Equation (25). From Equation (10) we can know that the coefficient of rolling friction of maize models has a higher fitting.

$$
y=71.875 x+20.506
$$

The contours of angle of repose under different coefficient of rolling friction are shown in Figure 16. From the Figure 16 we can see that the angle of repose varies greatly, and angle of repose increase with coefficient of rolling friction. Because the increased coefficient of rolling friction adds the rolling friction forces when the maize models acted with the others, which result in more likely to accumulate. Thus, the angle of repose becomes bigger.

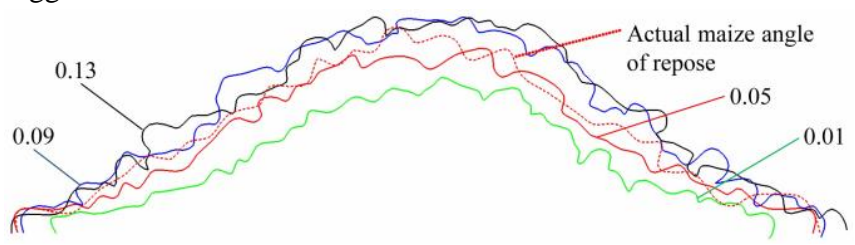

Figure 16 Simulation angle of repose under different coefficient of rolling friction of maize models

\subsubsection{Verification of simulation results}

845 maize seeds were produced according to the proportion of 13:14:3 as horse tooth shape, spherical cone shape, spherical shape in simulation. The fixed coefficient of static friction between maize seeds is 0.2. Comparing the simulation and actual angle of repose of maize models under aluminum cylinder from the Figure 17 , the average simulation, actual angle of repose is $27.83^{\circ}, 27.16^{\circ}$, respectively, and the relative error of which is $2.47 \%$. The simulation and actual maize angle of repose is basically $40 \mathrm{~mm}$ and the diameter is basically $170 \mathrm{~mm}$.

Comparing the simulation and actual angle of repose of maize models under organic glass from the Figure 18, the average simulation, actual angle of repose is $29.79^{\circ}, 28.93^{\circ}$, respectively, and the relative error of which is $2.97 \%$.

Comparing the simulation and actual angle of repose of maize seeds determinated by detailed prediction of coefficient of rolling friction of maize models under aluminum cylinder, the relative error of which is $0.22 \%$, while the relative error of that determinated by detailed prediction of coefficient of rolling friction of maize models is $2.47 \%$. In additon, comparing the simulation and actual angle of repose of maize seeds determinated by detailed prediction of coefficient of rolling friction of maize models under organic glass, the relative error of which is $0.31 \%$, while the relative error of that determinated by detailed prediction of coefficient of rolling friction of maize models is $2.97 \%$. 
Therefore, the detailed prediction of coefficient of rolling friction of maize models is more reliable.

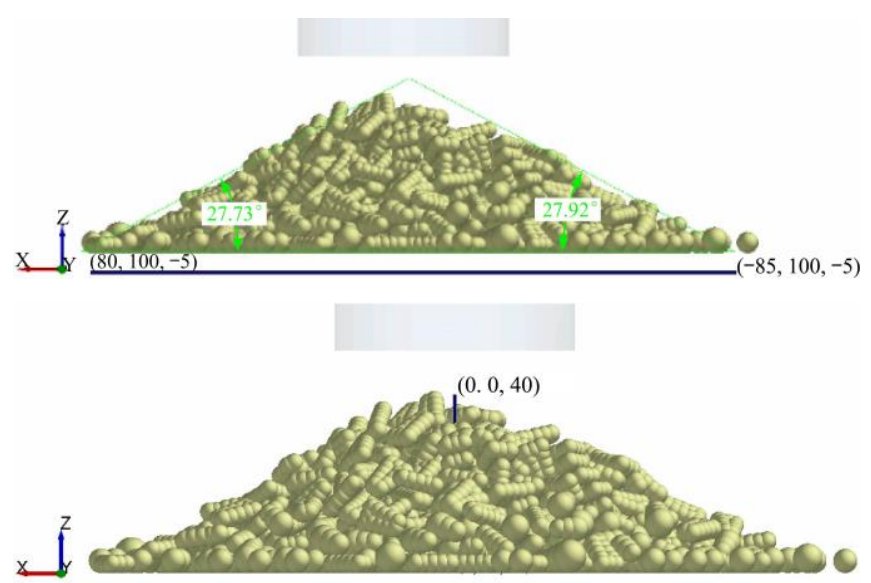

Figure 17 Generation of maize particle of maize angle of repose under the condition of aluminum cylinder container

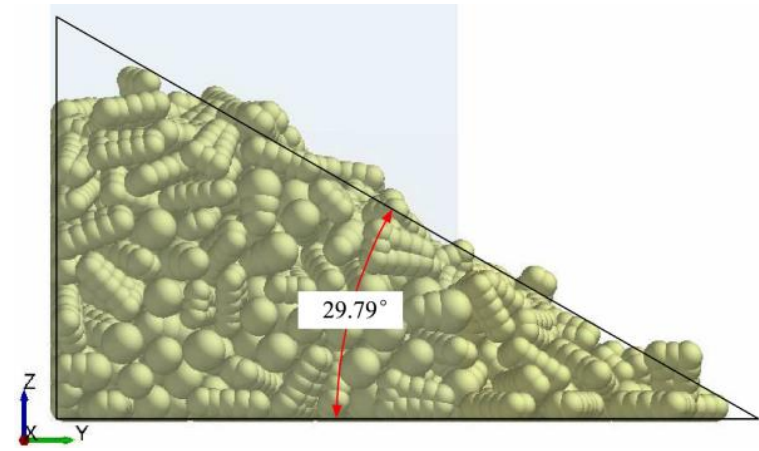

Figure 18 Generation of maize particle of maize angle of repose under the condition of organic glass container

\section{Effects of the inter-models coefficient of rolling friction on the particle behavior}

To study the effect of the coefficient of rolling friction determined by two methods obove on the flow and the engery change of maize models, the contacts number between maize models and the bottom plate is plotted as a function of time, as shown in Figure 19. From Figure 18, we know the initial contacts number is basically 60 . At $0 \mathrm{~s}$, some maize models start to fall from aluminum cylinder, and make sliding and rolling contact with each other. The coefficient of rolling friction increase the angle of repose of maize models and reduces the contacts number between maize models and the bottom plate. it can be observed especially that between 1.0-2.5 s, the effect of the contacts number between maize models and the bottom plate under the condition of detailed prediction of coefficient of rolling friction is more than united prediction of coefficient of rolling friction of maize models.

The rotational kinetic energy of all the maize models during the accumulation on the bottom plate is shown in Figure 20. The entire repose-formation process of maize models can be divided into three stages. In stage $1(0.0-0.44 \mathrm{~s})$, maize models begin to fall from the aluminum cylinder. As the support action of the bottom plate on the maize models, the maize models rotate slowly in the aluminum cylinder. In stage $2(0.44-1.64 \mathrm{~s})$, maize models fall from the aluminum cylinder onto the bottom plate and the maize models rotate rapidly from the potential energy of high position. In this process the rotational kinetic energy of the detailed prediction coefficient of rolling friction is bigger than the united prediction coefficient of rolling friction that has less impact on the rotational kinetic energy of maize models. In stage 3 (1.64-2.5 s), the rotational kinetic energy of the detailed prediction coefficient of rolling friction decreases slightly and is less than the combined coefficient of rolling friction.

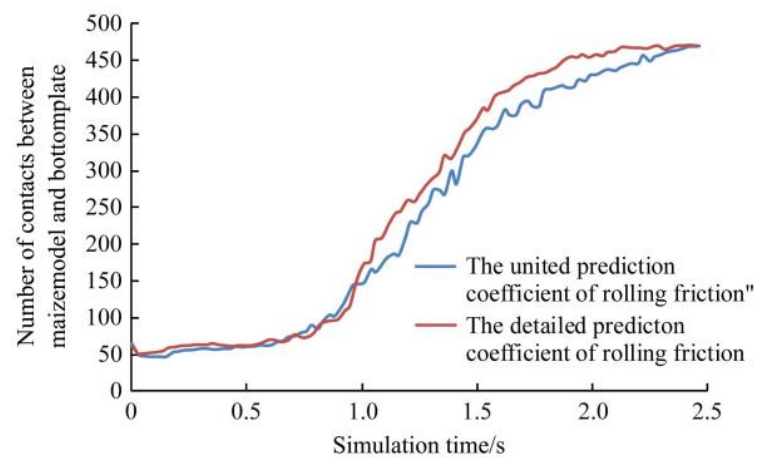

Figure 19 Effects of the inter-models coefficient of rolling friction obtained by two methods on the contacts number between maize models and bottom plate

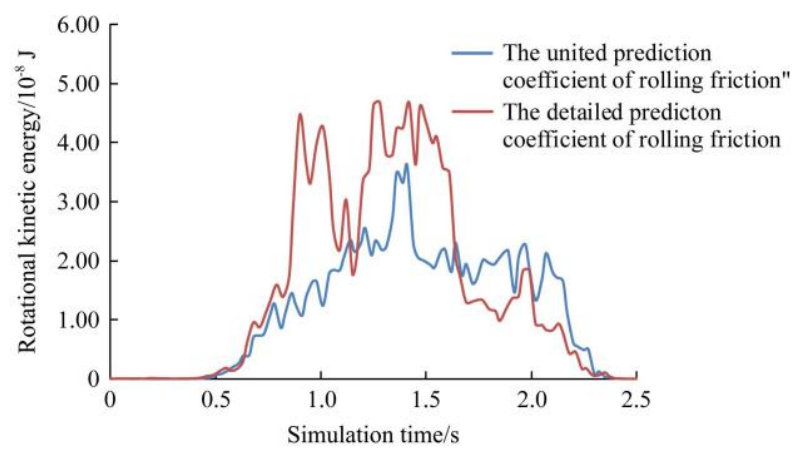

Figure 20 Effects of coefficients of rolling friction obtained by two methods on rotational kinetic energy of maize models during accumulation

The potential energy of the maize models is analyzed to reveal the mechanical behavior of the maize models. Figure 21 shows that the total potential energy varies with the detailed and united prediction coefficients of rolling friction when maize models fall from the aluminum cylinder onto the bottom plate. During the simulation period of $0.0-0.87 \mathrm{~s}$, the overall potential energy of the particles keeps an average of $1.14 \times 10^{-4} \mathrm{~J}$. Later, the overall potential energy decreases gradually with an outflow of maize models and the potential energy of the detailed coefficient of rolling friction fall faster than the combined coefficient of rolling friction. Because the coefficient of rolling friction of maize models between detailed and combined coefficients of rolling friction is different. At $2.21 \mathrm{~s}$, the overall potential energy of the particles approaches an average of $0.23 \times 10^{-4} \mathrm{~J}$.

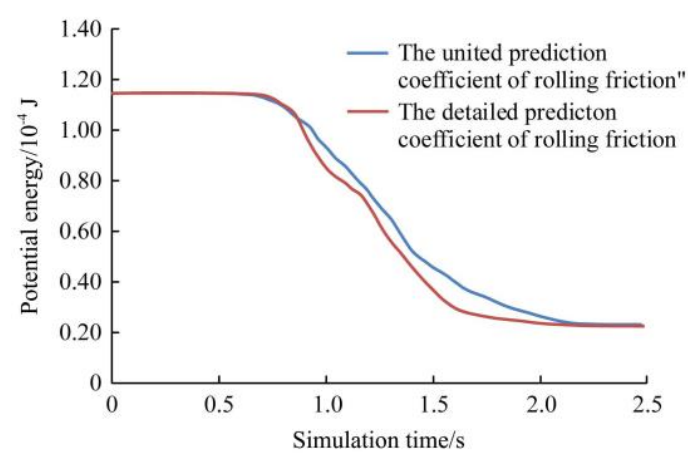

Figure 21 Effects of different coefficients of rolling friction obtained from two methods on the potential energy of maize models during accumulation 


\section{Discussion}

Although the difference between two method to determinate the coefficient of rolling friction of irregular maize models are different in the angle of repose and accumulation range of maize population is small, the contacts number between maize models and bottom plate, rotational kinetic energy of maize models, the potential energy have obviously different in accumulation process of the maize models. We should choose a better method to predict the coefficient of rolling friction of maize according to the application situation and investigation objective of irregular maize seeds.

\section{Conclusions}

1) This paper proposes a method to determinate the coefficient of rolling friction based on discrete element method (DEM) and physical experiments. Three types of maize models chose from five different shaped maize (including horse tooth shape, spherical cone shape, spherical shape) were developed with the help of slice modeling and 3D modeling technology. Aluminum cylinder container is used to arrange the simulation experiments of angle of repose with taking the coefficient of rolling friction as independent variables and the simulation angle of repose as target values. The results showed the predictive coefficient of rolling friction of horse tooth shape, spherical cone shape, spherical shape maize seeds is $0.023,0.062,0.13$, respectively, and the predictive coefficient of rolling friction between horse tooth shape and spherical shape, between spherical cone shape and spherical shape, between horse tooth shape and spherical cone shape maize seeds is $0.05,0.17$, 0.068 , respectively. Moreover, the angle of repose from two shape type mixed maize seeds are greater than that from one type shape of maize seeds as non-spherical maize seeds reduces the flow of maize seeds and increases the angle of repose of maize seeds. The horse tooth shape maize models are quite insensitive to the variation of the rolling coefficient of friction as shape of non-spherical maize seeds limiting the angle of repose in the accumulation process.

2) The simulation angle of reposes of maize models controlled by the detailed method were compared to the actual repose of angle under Aluminum cylinder, their relative error of which is $0.22 \%$, and their range of angle of repose is basically coincident. Also, the relative error is $0.31 \%$ under organic glass. The simulation angle of reposes of maize models controlled by the united method were compared to the actual repose of angle under Aluminum cylinder, their relative error of which is $2.47 \%$, and their range of angle of repose is basically coincident. Also, the relative error is $2.97 \%$ under organic glass. In addition, they have different in the contacts number between maize models and bottom plate, the change curve of the rotational kinetic energy, the potential energy of maize models is obvious different in accumulation process of the maize models controlled by two methods. Therefore, the detailed prediction of coefficient of rolling friction of maize models is more reliable.

\section{Acknowledgements}

This work was supported financially by the Chinese Natural Science Foundation (51405086, 51665001), Discipline construction fund project of Gansu Agricultural University (GAU- XKJS- 2018193).

\section{[References]}

[1] Owen P J, Cleary P W. Prediction of screw conveyor performance using the discrete element method (DEM). Powder Technology, 2012; 193(3): 269-282.

[2] Wang Y X, Liang Z J. Calibration method of contact characteristic parameters for corn seeds based on EDEM. Transactions of the CSAE, 2016; 32(22): 36-42. (in Chinese)

[3] Wensrich C M, Katterfeld A. Rolling friction as a technique for modelling particle shape in DEM. Powder Technology, 2012; 217(2): 409-417.

[4] Wiącek J, Molenda M, Horabik J, Jin Y O. Influence of grain shape and intergranular friction on material behavior in uniaxial compression: Experimental and DEM modeling. Powder Technology, 2012; 217(2): 435-442.

[5] Chen Z R, Yu J Q, Xue D M, Wang Y, Zhang Q, Ren L Q. An approach to and validation of maize-seed-assembly modelling based on the discrete element method. Powder Technology, 2018; 328(4): 167-183.

[6] Wiacek J, Molenda M, Horabik J, Ooi J Y. Influence of grain shape and intergranular friction on material behavior in uniaxial compression: Experimental and DEM modeling. Powder Technology, 2012; 217(2): 435-442.

[7] Höhner D, Wirtz S, Scherer V. Experimental and numerical investigation on the influence of particle shape and shape approximation on hopper discharge using the discrete element method. Powder Technology, 2013; 235: 614-627.

[8] Khazeni A, Mansourpour Z. Influence of non-spherical shape approximation on DEM simulation accuracy by multi-sphere method. Powder Technology, 2018; 332(6): 265-278.

[9] Balevičius R, Sielamowicz I, Mróz Z, Kačianauskas R. Effect of rolling friction on wall pressure, discharge velocity and outflow of granular materialfrom a flat-bottomed bin. Particuology, 2012; 10(6): 672-682.

[10] Han Y L, Jia F G, Tang Y R, Liu Y, Zhang Q. Influence of granular coefficient of rolling friction on accumulation characteristics. Acta Physica Sinica, 2014; 63(17): 533-538.

[11] Zeng Y, Jia F, Meng X, Han Y, Xiao Y. The effects of friction characteristic of particle on milling process in a horizontal rice mill. Advanced Powder Technology, 2018; 29(5): 1280-1290.

[12] Jayasundara C T, Yang R Y, Yu A B, Curry D. Discrete particle simulation of particle flow in IsaMill-effect of grinding medium properties. Chemical Engineering Journal, 2008; 135(1): 103-112.

[13] He Y, Evans T J, Yu A B, Yang R Y. DEM investigation of the role of friction in mechanical response of powder compact. Powder Technology, 2017; 319: 183-190.

[14] Wang L, Li R, Wu B, Wu Z, Ding Z. Determination of the coefficient of rolling friction of an irregularly shaped maize particle group using physical experiment and simulations. Particuology, 2017; 38(6): 185-195.

[15] Cui T, Liu J, Yang L, Zhang D X, Zhang R, Lan W. Experiment and simulation of rolling friction characteristic of corn seed based on high-speed photography. Transactions of the CSAE, 2013; 29(15): 34-41. (in Chinese)

[16] Wang Y X, Liang Z J, Zhang D X, Cui T, Shi S, Li K H, et al. Calibration method of contact characteristic parameters for corn seeds based on EDEM. Transactions of the CSAE, 2016; 32(22): 36-42. (in Chinese)

[17] Tanaka H, Momozo M, Oida A, Yamazaki M. Simulation of soil deformation and resistance at bar penetration by distinct element method. Journal of Terramechanics, 2000; 37(1): 41-56.

[18] ASAE. Compression test of food materials of convex shape, ASAE Standards 2002: Standards Engineering Practices 49, 2002; pp.592-599.

[19] Boac J M, Casada M E, Maghirang R G, Harner J P. Material and interaction properties of selected grains and oilseeds for modeling discrete particles, Trans. ASABE, 2010; 53(4): 1201-1216.

[20] Horabik J, Molenda M. Parameters and contact models for DEM simulations of agricultural granular materials: a review. Biosystems Engineering, 2016; 147: 206-225.

[21] González-Montellano C, Fuentes J M, Ayuga-Téllez E, Ayuga F. Determination of the mechanical properties of corn grains and olives required for use in DEM simulations. Journal of Food Engineering, 2012; 111(4): 553-562.

[22] Wang L J, Zhou W X, Ding Z J, Li X X, Zhang C G.. Experimental determination of parameter effects on the coefficient of restitution of differently shaped maize in three-dimensions. Powder Technology, 2015; 


$$
284 \text { (10): 187-194. }
$$

[23] Shi L R, Zhao W Y, Wu J M, Zhang F W, Sun W, Dai F, et al. Application of slice modeling technology in finite element analysis of agricultural products. Journal of Chinese Agricultural Mechanization, 2013; 6: 110-112. (in Chinese)

[24] Markauskas D, Kačianauskas R, Džiugys A, Navakas R. Investigation of adequacy of multi-sphere approximation of elliptical particles for DEM simulations. Granular Matter, 2010; 12(1): 107-123.

[25] Markauskas D, Ramírez-Gómez Á, Kačianauskas R, Zdancevičius E. Maize grain shape approaches for DEM modeling. Computers \& Electronics in Agriculture, 2015; 118(C): 247-258.

[26] Shi S. Design and experimental study of corn precision seed metering device with air pressure combined hole. Beijing: China Agricultural University, 2015; pp.27-51. 